EESTI NSV TEADUSTE AKADEEMIA TOIMETISED. GEOLOOGIA

ИЗВЕСТИЯ АКАДЕМИИ НАУК ЭСТОНСКОИ ССР. ГЕОЛОГИЯ

PROCEEDINGS OF THE ACADEMY OF SCIENCES OF THE ESTONIAN SSR. GEOLOGY

1984, 33, 1

удК $553.98 .042: 550$

Л. БУРЯКОВСКИИ, И. ДЖАФАРОВ

\title{
МОДЕЛИРОВАНИЕ СТРАТИГРАФИЧЕСКИХ ПОСЛЕДОВАТЕЛЬНОСТЕЙ В НЕМЫХ ТОЛЩАХ ПО ГЕОФИЗИЧЕСКИМ ДАННЫМ
}

В связи с-освоением морских нефтяных и газовых месторождений Азербайджана возникла проблема расчленения и моделирования разрезов как стратиграфических последовательностей по литологическим типам пластов в целях классификации и корреляции дробных стратиграфических подразделений в продуктивной толще. В литологическом отношении продуктивная толща представляет собой довольно однообразное чередование песчаных, алевритовых и глинистых разностей с соотношениями между песчано-алевритовыми разностями и глинами $1: 1$.

Мощность продуктивной толщи в шельфовой зоне Южного Каспия достигает 3500 м. В ряде случаев подошва продуктивной толщи не вскрывается буровыми скважинами, что не позволяет соотнести еe с фаунистически охарактеризованными подстилающими глинами понтического яруса (нижний плиоцен). Кровля продуктивной толщи залегает на глубине $1000-2500$ м. Надстилающий его верхний плиоцен расчленяется на́ акчагыльский и апшеронский ярусы, литологически представленные глинами, песчано-алевритовыми прослоями, мергелями, иногда известняками.

В практике нефтегеологических исследований шельфовой зоны Каспия основной каменный материал получают из глубоких буровых скважин. Вследствие малой величины керновых образцов и больших механических воздействий на породу в процессе бурения крайне редко извлекается макрофауна. Более надежным коррелятом является микрофауна и, в частности для разреза плиоцена, фораминиферы и остракоды. Так, для стратиграфического расчленения разреза плиоцена на ярусы (понтический, балаханский - продуктивная толща, акчагыльский и апшеронский) описано достаточное количество видов фораминифер и остракод, а также радиолярий и пелеципод.

Однако для более подробного расчленения продуктивной толщи на отделы и свиты палеонтологической информации уже недостаточно. Основное же препятствие для стратиграфических построений по данным микрофауны - весьма ограниченный (исчисляемый единицами) отбор керна из скважин, пробуренных в сложных торнотеолотических условиях. Достаточно указать, что разведочные скважины располагаются в открытом море на отдельных основаниях, имеют глубины, достигающие 6 тыс. м, и зачастую довольно сложный профиль из-за наклонно-направленного бурения. В таких случаях, когда нет сплошного отбора керна, единственной информацией, позволяющей -дать оценку всему разрезу, является промыслово-геофизическая.

В связи с вышесказанным была поставлена задача разработки методики моделирования средненормальных разрезов с естественной последовательностью залегания пластов по геофизическим параметрам, 
замеряемым в глубоких скважинах. Так как задача относится к многомерным, для ее решения были привлечены кластерный анализ и марковская процедура моделирования.

Если в $n$ объектах измеряется $m$ характеристик, то множество данных образует матрицу порядка $[n \times m]$. Сущность кластерного анализа заключается в получении симметричной матрицы порядка $[n \times n]$ путем использования одной из мер сходства-коэффициента корреляции $r=\operatorname{cov} x, y /(\operatorname{var} x \cdot \operatorname{var} y)^{1 / 2}$ или стандартизованного $m$-мерного евкли . дова расстояния $d_{i j}=\left[\boldsymbol{\Sigma}\left(x_{i k}-x_{j k}\right)^{2} / m\right]^{1 / 2}$, где $i, j=1, \ldots, n$ и $k=1, \ldots, m$. и в получении иерархической группировки объектов по оценкам их сходства. Марковскую цепь первого порядка можно определить как описание переходов между различными состояниями, когда вероятности каждого перехода зависят от непосредственно предшествующего состояния.

Выбранные процедуры были реализованы на месторождении Булламоре, где по скважинам 29 и 32 были выделены пласты от подошвы VII горизонта до кровли V горизонта (верхний отдел продуктивной толщи). Выделение пластов проводили визуально по каротажным диаграммам d учетом характерных признаков, соответствующих тем или иным литологическим разностям. В скважине 29 выделили 26, а в скважине $32-66$ пластов. По каждому пласту были определены: мощность $H$ (толщина пласта), диаметр скважины по кавернометрии $d_{\Phi}$, значение кажущихся удельных электрических сопротивлений по пяти зондам бокового каротажного зондирования (БКЗ) @к, значение электрических сопротивлений по боковому каротажу @вк, относительные величины потенциала собственной поляризации $\alpha$ пс и естественното гамма-излучения $\Delta I_{\gamma}$. В итоге была получена матрица исходных данных $[n \times m]$, где $n=92$ пласта, а $m=10$ признаков.

С помощью пропраммы «Кластер» на ЭВМ БЭСМ-6 по нормированным признакам были вычислены как коэффициенты корреляции, так и обобщенные эвклидовы расстояния и построены соответствующие дендрограммы для 92 пластов методом средневзвешенного попарного группирования. Как видно (рис. 1), в пределах V-VII горизонтов месторождения Булла-море выделяются пять весьма четких групп пластов. Анализ кернового материала, сопоставление этих групп с каротажными диаграммами и результатами опробования позволили охарактеризовать эти группы по литологии и характеру насыщения. В табл. 1 показаны пределы изменения и средние значения основных геофизических пाараметров: $\varrho_{K ; 2,25} ; \alpha_{п c} ; \Delta I_{\gamma} ; d_{\Phi}$ по выделенным группам пластов.

Для пределов и средних значений удельных электрических сопротивлений по пяти зондам БКЗ для каждой группы пластов (табл. 2) были построены кривые зондирования и получены значения истинных удельных сопротивлений @п, сопоставленные со значениями, полученными по данным бокового каротажа евк (табл. 1).

Интересно отметить, что в изучаемом разрезе имеются два литологически разных типа продуктивных пластов, которые различаются по геофизическим характеристикам, Один из них характеризуется более высокими значениями амплитуд ПС $(0,31-0,90)$ и низкими сопротивлениями от 6,5 до 15 Ом·м; другой - более низкими значениями амплитуд ПС $(0,17-0,41)$ и повышенными сопротивлениями от 16,5 до 29. ОМ $\cdot$ м (табл. 1, 2).

По результатам классификации пластов как по коэффициентам корреляции, так и по обобщенным эвклидовым расстояниям, были составлены матрицы частот переходов одной выделенной литологической разности в другую по пластам, а по соответствующим частотам рас- 


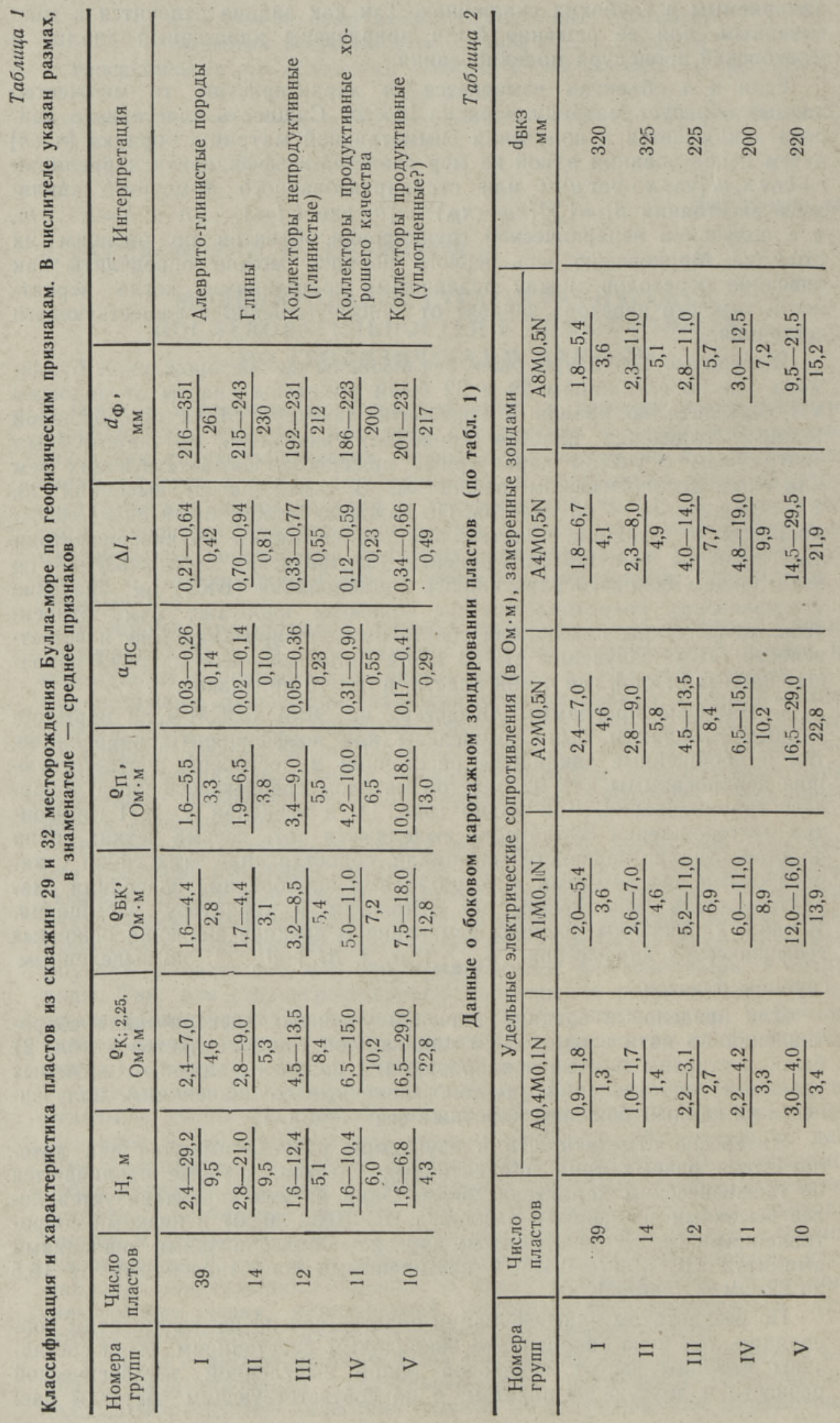




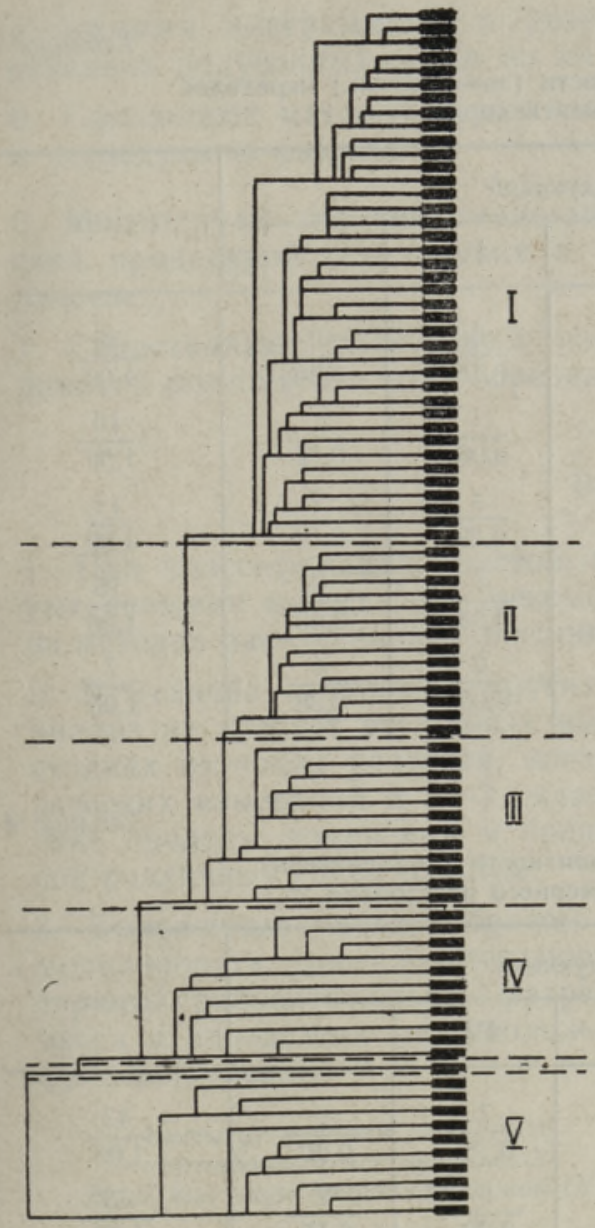

Рис. 1. Классификация разреза V-VII горизонтов месторождения Булла-море по геофизическим параметрам.

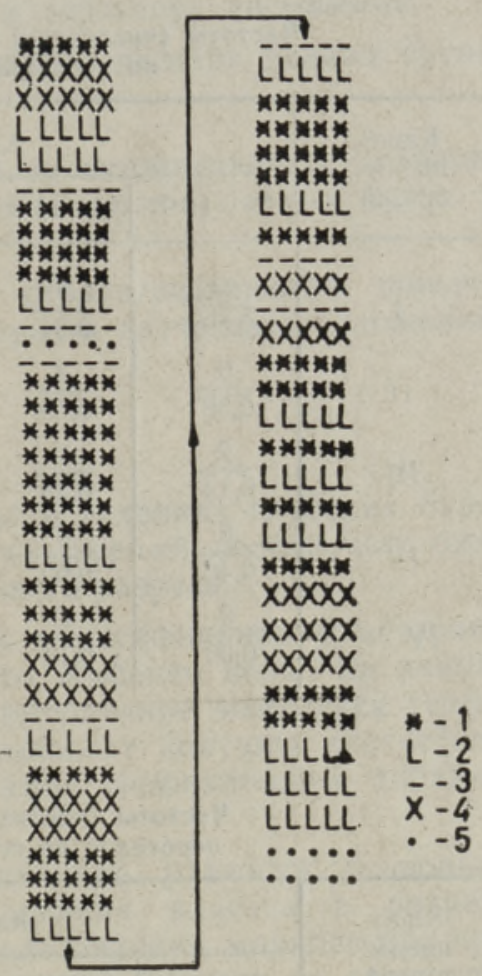

Рис. 2. Моделирование нормального разреза в интервале V-VII горизонтов месторождения Булла-море (скв. 32). 1 алевритоглинистые пачкн; 2 глины; 3 - коллекторы непродуктивные (глинистые); 4 коллекторы продуктивные хорошего качества; 5 - коллекторы продуктивные (уплотненные).

считаны матрицы вероятностей переходов (табл. 3, 4), которые легли в основу моделирования разреза (рис. 2).

Моделирование стратиграфической последовательности пластов с использованием матрицы вероятностей переходов состоит из следующих операций: 1) случайный выбор исходного пласта, принадлежащего какой-либо группе; 2) ${ }^{*}$ выбор следующего пласта в соответствии с вероятностью перехода первото пласта во второй из строки матрицы переходных вероятностей, соответствующей выбранной группе пластов; 3) продолжение процедуры до тех пор, пока не будет исчерпано заданное число переходов.

Таким образом, при моделировании стратиграфической последовательности, т. е. при построении искусственного разреза, выбор типа породы осуществляется в соответствии с матрицей вероятностей переходов. В использованном алгоритме каждый пласт имеет единичную мощность, равную средней мощности всех пластов в разрезе. Более сложный алгоритм позволяет моделировать разрезы с учетом распределений измеренных мощностей пластов по каждой из литологических прупп. Полученный разрез может служить в качестве сводного геологогеофизического разреза. Привязка разреза к стратиграфической 
Частоты (числитель) и вероятности (знаменатель) переходов по величине коэффициента корреляции, r

\begin{tabular}{c|c|c|c|c|c|c}
\hline \multirow{2}{*}{$\begin{array}{c}\text { Класс } \\
\text { преды- } \\
\text { дущий }\end{array}$} & \multicolumn{5}{|c|}{ Класс последующий } & \multirow{2}{*}{ Сумма } \\
\cline { 2 - 6 } I & I & II & III & IV & V & \\
\hline \multirow{2}{*}{ II } & $\frac{23}{0,59}$ & $\frac{8}{0,21}$ & $\frac{2}{0,05}$ & $\frac{6}{0,15}$ & $\frac{0}{0,00}$ & $\frac{39}{1,00}$ \\
III & $\frac{6}{0,38}$ & $\frac{3}{0,19}$ & $\frac{4}{0,25}$ & $\frac{1}{0,06}$ & $\frac{2}{0,12}$ & $\frac{16}{1,00}$ \\
IV & $\frac{2}{0,14}$ & $\frac{5}{0,36}$ & $\frac{1}{0,07}$ & $\frac{4}{0,29}$ & $\frac{2}{0,14}$ & $\frac{14}{1,00}$ \\
V & $\frac{6}{0,40}$ & $\frac{0}{0,00}$ & $\frac{4}{0,27}$ & $\frac{5}{0,33}$ & $\frac{0}{0,00}$ & $\frac{15}{1,00}$ \\
$\frac{0}{0,00}$ & $\frac{1}{0,14}$ & $\frac{2}{0,28}$ & $\frac{0}{0,00}$ & $\frac{4}{0,58}$ & $\frac{7}{1,00}$
\end{tabular}

Таблица 4

Частоты (числитель) и вероятности (знаменатель) переходов по величине $m$-мерного расстояния, $\boldsymbol{d}_{i j}$

\begin{tabular}{c|c|c|c|c|c|c}
\hline \multirow{2}{*}{$\begin{array}{c}\text { Класс } \\
\text { преды- }\end{array}$} & \multicolumn{5}{|c|}{ Класс последующий } & Суима \\
\cline { 2 - 5 } & I & II & III & IV & V & \\
\hline \multirow{2}{*}{ I } & $\frac{27}{0,63}$ & $\frac{6}{0,14}$ & $\frac{3}{0,07}$ & $\frac{7}{0,16}$ & $\frac{0}{0,00}$ & $\frac{43}{1,00}$ \\
II & $\frac{4}{0,31}$ & $\frac{4}{0,31}$ & $\frac{3}{0,23}$ & $\frac{0}{0,00}$ & $\frac{2}{0,15}$ & $\frac{13}{1,00}$ \\
III & $\frac{3}{0,21}$ & $\frac{4}{0,30}$ & $\frac{2}{0,14}$ & $\frac{2}{0,14}$ & $\frac{3}{0,21}$ & $\frac{14}{1,00}$ \\
IV & $\frac{6}{0,60}$ & $\frac{0}{0,00}$ & $\frac{2}{0,20}$ & $\frac{2}{0,20}$ & $\frac{0}{0,00}$ & $\frac{10}{1,100}$ \\
V & $\frac{1}{0,09}$ & $\frac{1}{0,09}$ & $\frac{3}{0,27}$ & $\frac{0}{0,00}$ & $\frac{6}{0,55}$ & $\frac{11}{1,00}$
\end{tabular}

колонке осуществляется с помощью каротажных реперов, к которым, в данном случае, относятся глинистый раззрез между V и VII горизонтами и подошва VII горизонта, являющаяся кровлей надкирмакинской глинистой свиты.

В итоге, для решения поставленной задачи выполняются следующие процедуры.

1. В изучаемых разрезах по комплексу геофизических измерений выделяют пласты и определяют значения геофизических параметров для каждого пласта.

2. Составляют матрицу $[n \times m]$, тде $n-$ количество пластов, $m-$ количество геофизических параметров.

3. Обрабатывают полученную матрицу в целях классификации пластов поо группам.

4. Сопоставляют группы пластов с данными исследования кернов, ка- 
ротажными диаграммами и результатами опробования пластов для описания полученных групп по литологии и характеру насыщения.

5. Составляют матрицу вероятностей переходов пластов разных трупп в нсследуемом разрезе.

6. Моделируют средненормальный разрез в соответствии с марковской процедурой чередования и следования пластов разных групп в разрезе.

7. Сопоставляют полученный разрез со стратиграфической шкалой данного региона с целью определения возраста изучаемых отложений.

\section{Выводы}

1. При классификации пластов, изученных в условиях глубоких буровых скважин может быть рекомендован кластерный анализ, как один из методов расчленения и описания осадочного разреза.

2. В отличие от многих других методов классификации кластерный анализ не требует эталонных выборок, что особенно ценно на ранних стадиях изучения разрезов, копда лишь выполнение комплекса теофизических измерений в $2-3$ скважинах позволяет получить статистические пределы изменения и средние значения теофизических параметров различных групп пластов.

3. Выделенные таким образом литологические разности позволяют моделировать последовательность чередования пластов в разрезе, строить средненормальные разрезы с использованием марковского процесса и определять местоположение различных пластов на стратиграфической шкале.

Ннститут проблем глубинных нефтегазовых месторождений Академии наук Азербайджанской ССР
Поступила в редакцию 10/V 1982

\section{BURJAKOVSKI, I. DZAFAROV}

\section{TUMMADE KIHTIDE STRATIGRAAFILISE JARJESTUSE MODELLEERIMINE GEOFUOSIKALISE TEABE POHJAL}

Puuraukudes ettenähtud geofüüsikaliste uuringute põhjal on välja töötatud settekivimite kihtide klassifitseerimise ja vastavate läbilöigete modelleerimise metoodika. Ulesanne on realiseeritud arvutil $\mathrm{Б} Э \mathrm{CM} 6$, kihtide rühmitamiseks on kasutatud klasteranalüüsi ja läbilōigete modelleerimiseks Markovi ahelaid.

\section{BURYAKOVSKY, I. DJAFAROV}

\section{SIMULATION OF STRATIGRAPHIC SUCCESSION IN BARREN STRATA ACCORDING TO GEOPHYSICAL DATA}

The authors have set and solved the problem of the development of reservoir classification methods of sedimental sections simulation on the basis of a geophysical field investigations complex. For the solution of this problem, the group analysis method (cluster analysis) and Markov's procedure of simulation using matrix of transitions probabilities were used and realized with the help of the computer BESM-6. 